\title{
Tightly regulated and inducible expression of a yoked hormone-receptor complex in HEK 293 cells
}

\author{
T P Meehan, D Puett and P Narayan \\ Department of Biochemistry and Molecular Biology, University of Georgia, Athens, Georgia 30602, USA \\ (Requests for offprints should be addressed to P Narayan, Department of Biochemistry and Molecular Biology, B320B Life Sciences Building, \\ University of Georgia, Athens, GA 30602-7229, USA; Email: narayan @ bmb.uga.edu)
}

\begin{abstract}
We have previously reported the construction of a constitutively active luteinizing hormone receptor by covalently linking a fused heterodimeric hormone to the extracellular domain of the $G$ protein-coupled receptor. This yoked hormone-receptor complex (YHR) was found to produce high levels of cAMP in the absence of exogenous hormone. Stable lines expressing YHR were generated in HEK 293 cells to obtain lines with different expression levels; however, in a relatively short time of continued passage, it was found that YHR expression was greatly reduced. Herein, we describe the development of clonal lines of HEK 293 cells in which the expression of YHR is under the control of a tetracycline-regulated system. Characterization of clonal lines revealed tight control of YHR expression both by dose and time of incubation with doxycycline. These experiments demonstrated a good correlation between expression levels of the receptor and basal CAMP production. Moreover, the reduction in receptor expression following doxycycline removal revealed that YHR mRNA and protein decayed at similar rates, again suggesting a strong linkage between mRNA and protein levels. The controlled expression of YHR in this cell system will allow for a more detailed analysis of the signaling properties associated with constitutive receptor activation and may prove to be advantageous in developmental studies with transgenic animals.
\end{abstract}

Journal of Molecular Endocrinology (2004) 32, 247-255

\section{Introduction}

The luteinizing hormone receptor (LHR) is necessary for reproduction in mammals. Binding and signaling through LHR by luteinizing hormone or chorionic gonadotropin $(\mathrm{CG})$ primarily leads to an increase in the intracellular levels of cAMP. LHR activation is responsible for gonadal steroidogenesis, ovulation, and male sexual differentiation (Ascoli et al. 2002).

We have previously reported several studies that have utilized a fusion protein of the gonadotropin hormone, human chorionic gonadotropin (hCG), with its receptor, LHR, to examine various structure-function aspects of receptor activation in cell culture (Wu et al. 1996, Narayan et al. 2002). When transiently expressed in COS-7 or HEK 293 cells, this yoked hormone-receptor complex (YHR) led to elevated levels of basal cAMP, suggesting that the receptor in this fusion protein was activated by the attached ligand. In this respect,
YHR is similar to mutations in LHR that result in constitutively activated receptors. The latter have been implicated in familial male-limited precocious puberty, a disorder characterized by increased prepubertal testosterone levels and Leydig cell hyperplasia (Themmen \& Huhtaniemi 2000, Shenker 2002). More recently, we have demonstrated that YHR is functional in vivo and causes prepubertal increases in testosterone and estrogen in male and female transgenic mice respectively, in addition to affecting testicular and ovarian development (Meehan et al. 2002).

Unlike LHR, quantitative measurements of YHR expression and receptor dynamics cannot be performed by standard ligand binding assays, since the tight association of the covalently attached ligand with the receptor inhibits binding of exogenous hCG (Wu et al. 1996). In order to avoid the inherent variability in expression observed with transient transfections, we established a stable cell line of YHR in HEK 293 cells that could be used as 


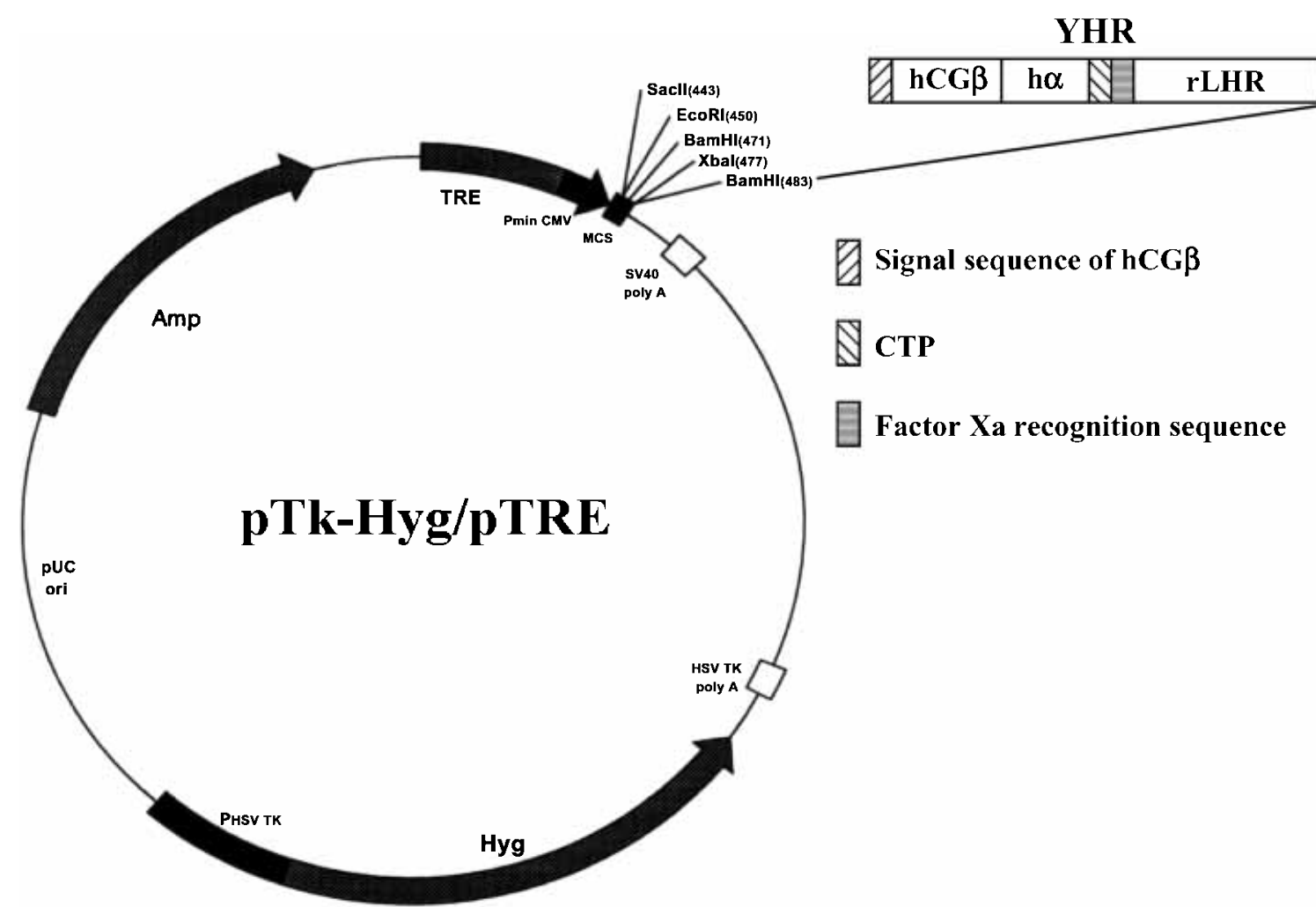

Figure 1 Schematic diagram of pTk-hyg/pTRE-YHR. A single plasmid was generated containing both the hygromycin resistance gene and the tet-responsive element. YHR, cloned into the multiple cloning site, consists of the hCG $\beta$-subunit covalently linked via its CTP to the human $\alpha$-subunit (h $\alpha)$ which is, in turn, linked to RAT (r) LHR via an additional CTP and a factor Xa cleavage sequence.

a standard cell line for further structure-function and signaling studies. However, it was found that YHR protein expression was readily lost with continued passage of the cells. Although the cause of this loss is not clear, it was reasoned that chronic activation of the receptor may be responsible.

As a possible solution to this problem, we decided to develop a regulated cell culture system wherein expression of YHR could be controlled and maintained. Additionally, such a system would facilitate further studies on gonadal development in YHR transgenic mice. For this purpose, we chose to develop the tetracycline-regulated system of Gossen and Bujard (1992). The Tet-on system allows for tight control of gene expression in the presence of the tetracycline analog, doxycycline (Dox) (Gossen et al. 1995). Dox binds to the reverse tetracycline repressor protein (rTetR), which is fused to the VP16 activation domain of the herpes simplex virus. This activated fusion protein binds to the tetracycline response element (TRE) that, in turn, drives expression of the protein of interest.

Herein, we describe the establishment and characterization of cells expressing YHR (YHR-tet) in a controlled manner by utilization of the Tet-on system. In YHR-tet cell lines, expression was tightly controlled both by the dose and time of exposure to Dox. The level of YHR expression correlated well with the level of intracellular cAMP indicating that this will be a useful system for further studies on YHR-mediated signaling.

\section{Materials and methods}

\section{Establishment of stable lines in HEK 293 cells}

The YHR cDNA was subcloned into the expression vector pcDNA3 (Invitrogen, Carlsbad, CA, USA) wherein expression of YHR is under the control of the cytomegalovirus (GMV) promoter. 
$\mathbf{A}$

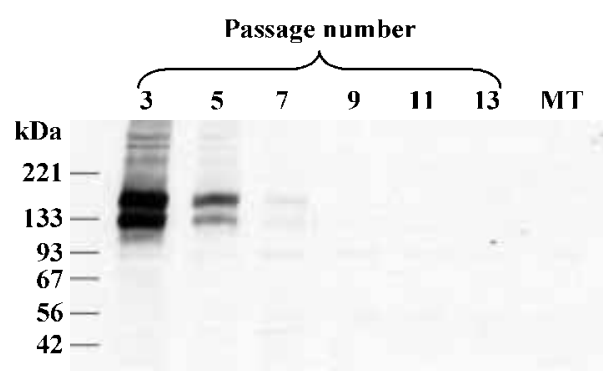

B

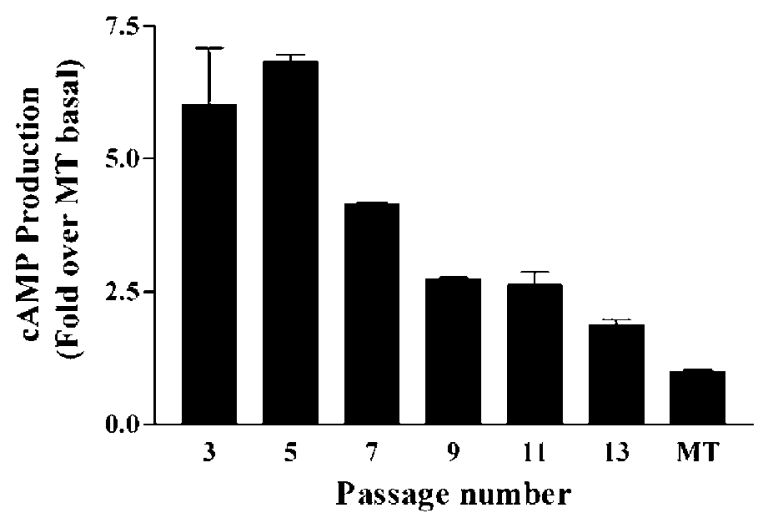

Figure 2 Loss of YHR expression from stable lines in HEK 293 cells. The expression of YHR was followed in an HEK 293 stable line between passages 3 and 13 by (A) Western blot analysis on $10 \mu \mathrm{g}$ total membrane protein resolved on a $10 \%$ SDS PAGE gel under reducing conditions (sizes of molecular mass standards are shown), and (B) basal cAMP production on similar passages of cells. Data shown are means \pm ranges of a representative experiment. MT, mock-transfected.

Stable HEK 293 cell lines expressing YHR were established by transfection of YHR cDNA with Lipofectamine (Invitrogen) according to the manufacturer's instructions, followed by selection with $700 \mu \mathrm{g} / \mathrm{ml} \mathrm{Geneticin} \mathrm{(Invitrogen)} \mathrm{for} 2$ weeks. The surviving cells were maintained in DMEM $(4.5 \mathrm{~g} / 1$ glucose) containing $10 \%$ horse serum, $100 \mathrm{U} / \mathrm{ml}$ penicillin, $\quad 100 \mu \mathrm{g} / \mathrm{ml}$ streptomycin, $0.25 \mu \mathrm{g} / \mathrm{ml}$ amphotericin B, and $400 \mu \mathrm{g} / \mathrm{ml}$ Geneticin. Expression of YHR was determined by Western blot analysis of total cell membranes and basal cAMP production as described below.

\section{Cloning of pTk-hyg/pTRE-YHR}

The pTk-hyg and pTRE plasmids (BD Biosciences Clontech, Palo Alto, CA, USA) were combined by ligating the $1063 \mathrm{bp}$ EarI fragment from pTRE containing the TRE and multiple cloning site (MCS) into the unique EarI site in pTk-hyg, thus generating a single plasmid which contains both the hygromycin (hyg) resistance gene and the inducible TRE promoter (Fig. 1). YHR cDNA was cloned into the BamHI site of the MCS. YHR consists of the $\beta$-subunit of hCG linked to the common human $\alpha$-subunit via its $\mathrm{C}$-terminal peptide (CTP). This complex, in turn, is linked to the rat LHR via an additional CTP and a Factor Xa cleavage site (Fig. 1).

\section{Establishment of double stable 293 Tet-on cell lines}

HEK 293 Tet-on cells were obtained from BD Biosciences Clontech and grown in $\alpha$-MEM containing $10 \%$ fetal bovine serum, $100 \mathrm{U} / \mathrm{ml}$ penicillin, $100 \mu \mathrm{g} / \mathrm{ml}$ streptomycin, $0.25 \mu \mathrm{g} / \mathrm{ml}$ amphotericin B, and $100 \mu \mathrm{g} / \mathrm{ml}$ Geneticin. Cells at $70 \%$ confluency were transfected with $10 \mu \mathrm{g}$ of either pTk-hyg/pTRE or pTk-hyg/pTRE-YHR utilizing Lipofectamine. Following transfection, cells were selected for antibiotic resistance by incubation with $200 \mu \mathrm{g} / \mathrm{ml}$ hygromycin. Twenty colonies from each transfection were isolated using cloning cylinders, and clonal cell lines were established that were tested for the expression of YHR in the presence and absence of $2 \mu \mathrm{g} / \mathrm{ml}$ Dox (BD Biosciences Clontech) by Western blot analysis and determination of basal cAMP production. Cell lines established with colonies from the pTk-hyg/ pTRE transfection (mock transfection, MT) were utilized as controls.

\section{Total cell membrane preparation and Western blot analysis}

Total cell membranes were prepared by homogenization in $50 \mathrm{mM}$ Tris- $\mathrm{HCl}, \mathrm{pH} 7 \cdot 5$, containing $250 \mathrm{mM}$ sucrose and protease inhibitors (1 mM phenylmethylsulfonyl fluoride, $5 \mathrm{mM} \mathcal{N}$ ethylmaleimide, and $2 \mathrm{mM}$ EDTA). A low speed $(1000 \times \boldsymbol{g})$ centrifugation removed cellular debris and nuclei, and the supernatant was subjected to a high speed spin $(48000 \times \boldsymbol{g})$ for $45 \mathrm{~min}$ to pellet total cellular membranes. The membrane fraction 
A

\section{Clone}

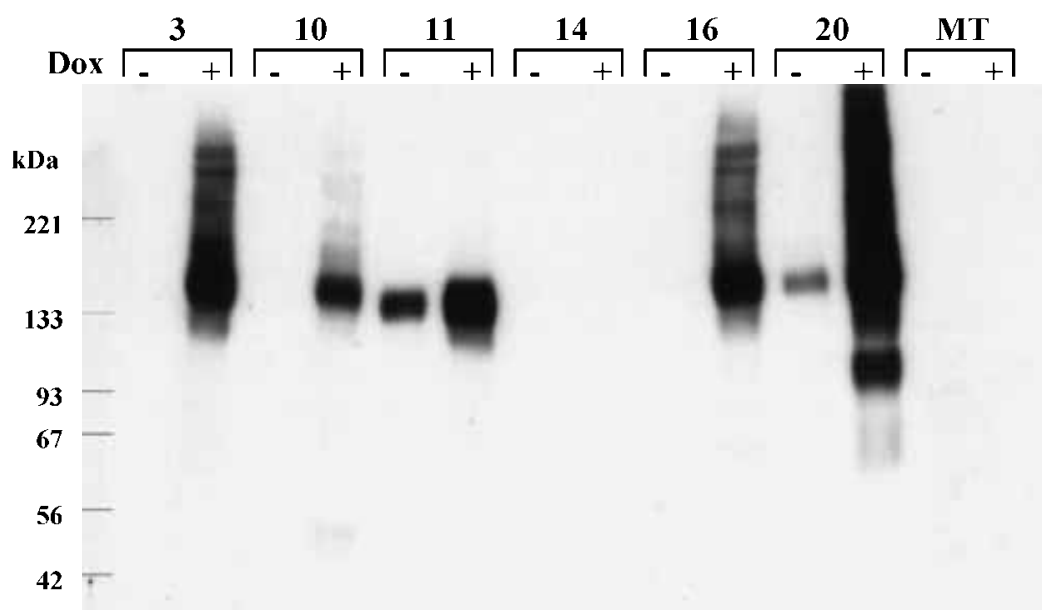

B

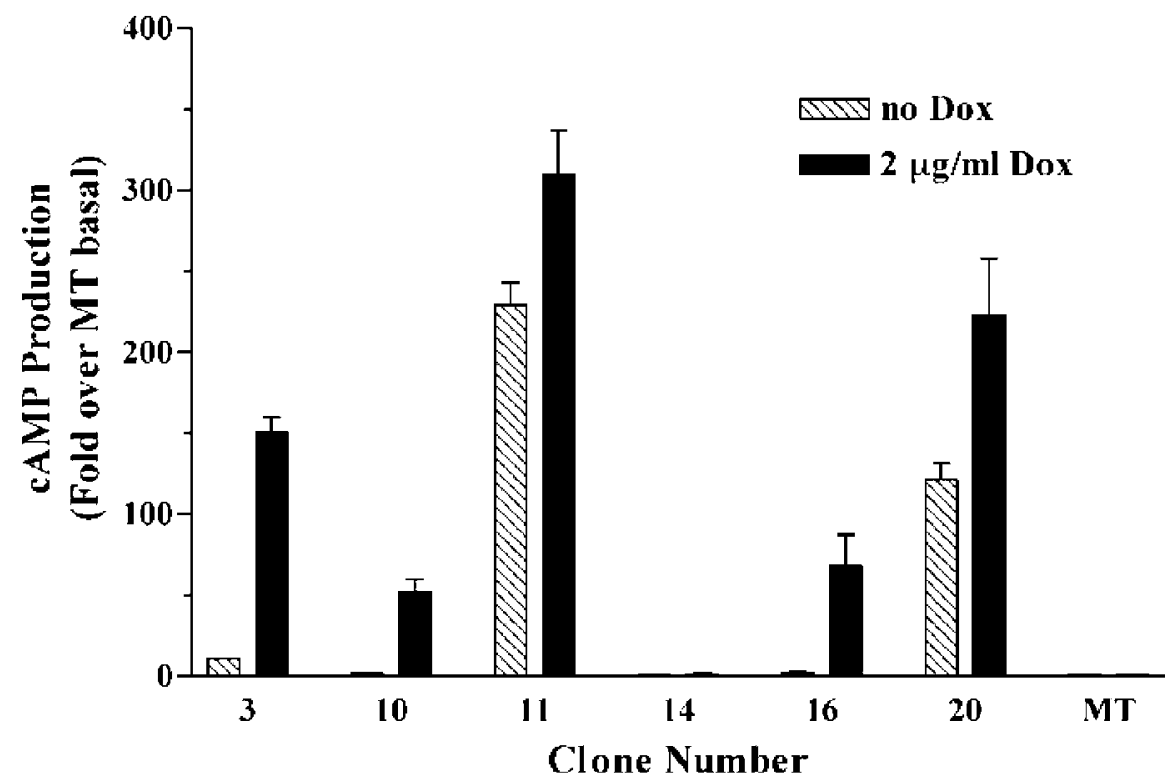

Figure 3 Establishment of tet-responsive lines expressing YHR. Following transfection of pTK-hyg/pTRE-YHR into HEK 293 Tet-on cells and selection with $200 \mu \mathrm{g} / \mathrm{ml}$ hygromycin, YHR-expressing clones were characterized by Western blot analysis (A) and basal cAMP production (B). Cells from each clone were treated with or without $2 \mu \mathrm{g} / \mathrm{ml}$ Dox for $48 \mathrm{~h}$, and the clones presented here are representative of all those tested. Sizes of molecular mass standards are indicated; basal cAMP production is expressed as fold-increase over mock-transfected (MT) basal, and data are means \pm ranges of two independent experiments. 
was resuspended in $50 \mathrm{mM}$ Tris- $\mathrm{HCl}, \mathrm{pH} 7 \cdot 5$, containing protease inhibitors, and protein content was determined by BCA assay (Pierce, Rockford, IL, USA). Total cell membrane proteins $(10 \mu \mathrm{g})$ were resolved on a 10\% SDS PAGE gel

A

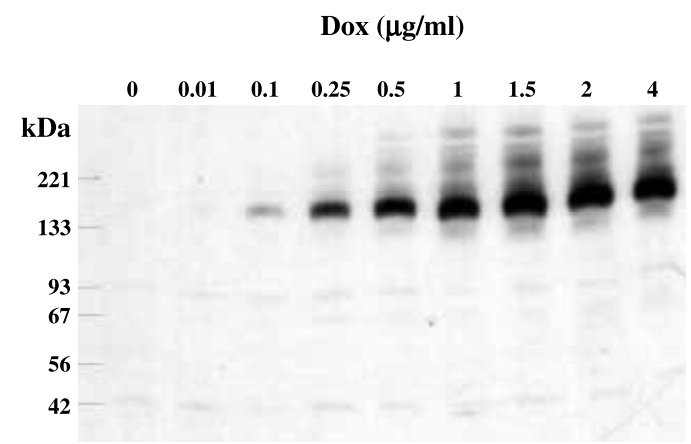

B

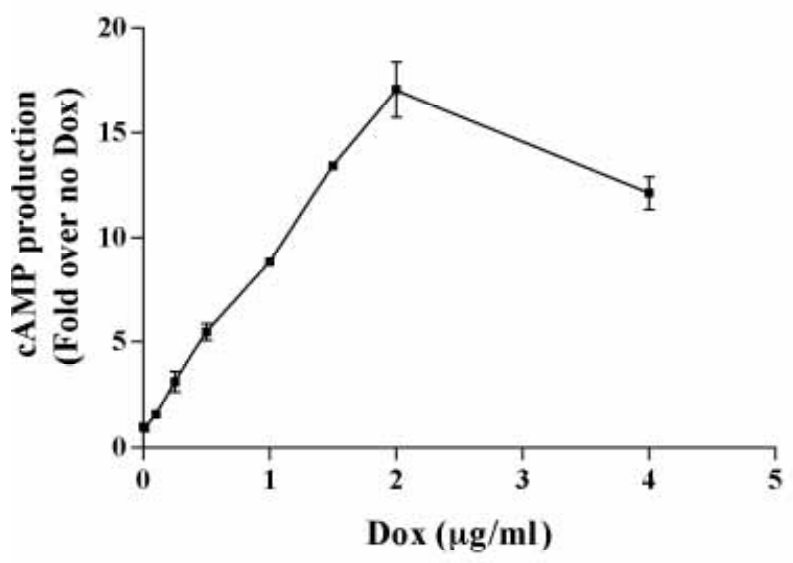

C

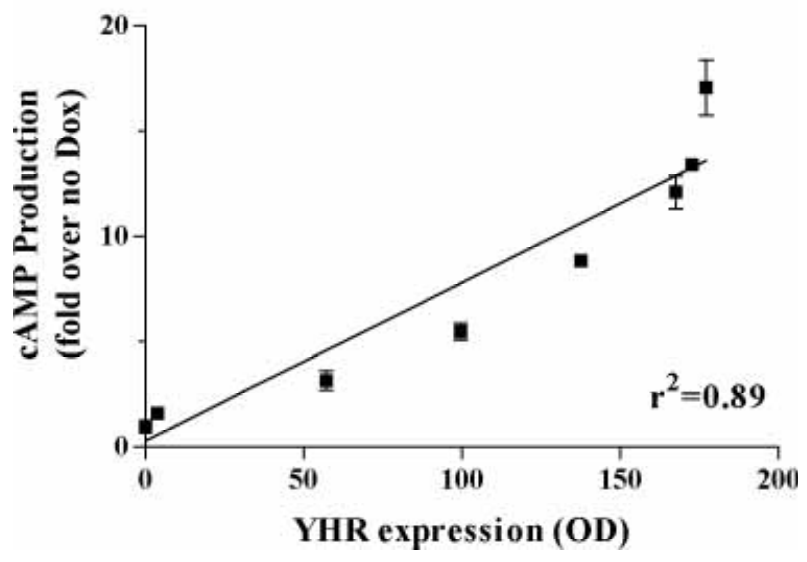

under reducing conditions and transferred to Immobilon-P (Millipore, Bedford, MA, USA). Following blocking for $2 \mathrm{~h}(10 \mathrm{mM}$ Tris-HCl, $\mathrm{pH}$ $7 \cdot 5,0 \cdot 5 \mathrm{M} \mathrm{NaCl}, 0 \cdot 2 \%$ Tween-20, and $3 \%$ bovine serum albumin), the blot was incubated for $1 \mathrm{~h}$ with a 1/1000 dilution of a polyclonal antibody to the CTP of hCG $\beta$ (kindly provided by Dr Vernon Stevens, Ohio State University). After incubation with an anti-rabbit HRP (horseradish peroxidase) (Amersham Biosciences, Piscataway, NJ, USA), the blot was developed with SuperSignal ECL (Pierce).

\section{cAMP assay}

Cells were plated in a 12-well plate and, after the appropriate treatment with Dox, washed twice in Waymouth $/ 0 \cdot 1 \%$ BSA, followed by incubation for $45 \mathrm{~min}$ at $37^{\circ} \mathrm{C}$ in Waymouth/BSA/0.8 mM isobutylmethylxanthine to mimic the stimulation time normally utilized for LHR signaling assays. Intracellular cAMP was collected by treating the cells with $100 \%$ ethanol overnight at $-20^{\circ} \mathrm{C}$ and dried in a speedvac. cAMP levels were determined by RIA (Perkin Elmer, Boston, MA, USA).

\section{Northern blot analysis}

mRNA was prepared from cells using the Fast Track $2 \cdot 0$ kit (Invitrogen), followed by resolution of $4 \mu \mathrm{g}$ on a $1 \cdot 2 \%$ agarose gel containing $6 \%$ formaldehyde. mRNA was transferred to a Zeta probe nylon membrane (Bio-Rad, Hercules, CA, USA) by capillary action. Following prehybridization $(50 \%$ formamide, $5 \times$ Denhardt's, $5 \times \mathrm{SSPE}$, $1 \% \mathrm{SDS}$, and $100 \mu \mathrm{g} / \mathrm{ml}$ salmon sperm DNA) at $42{ }^{\circ} \mathrm{C}$ for $4 \mathrm{~h}$, the membrane was probed overnight at $42{ }^{\circ} \mathrm{C}$ in the above buffer with $5 \times 10^{6}$ c.p.m. of a ${ }^{32} \mathrm{P}$ probe made to either the cDNA of YHR or human actin $\beta$-subunit by random primed

Figure 4 Dose-response of Dox on YHR-expressing cell lines. YHRtet-16 cells were incubated with increasing concentrations of Dox from 0 to $4 \mu \mathrm{g} / \mathrm{ml}$ for $48 \mathrm{~h}$ followed by (A) Western blot analysis and (B) measurement of basal cAMP production (cAMP values were expressed as fold over 'no Dox' basal). Data are means \pm ranges of two independent experiments. (C) Densitometry was performed on the X-ray film from the Western blot, and YHR expression was graphed versus cAMP production using linear least squares analysis. 
A

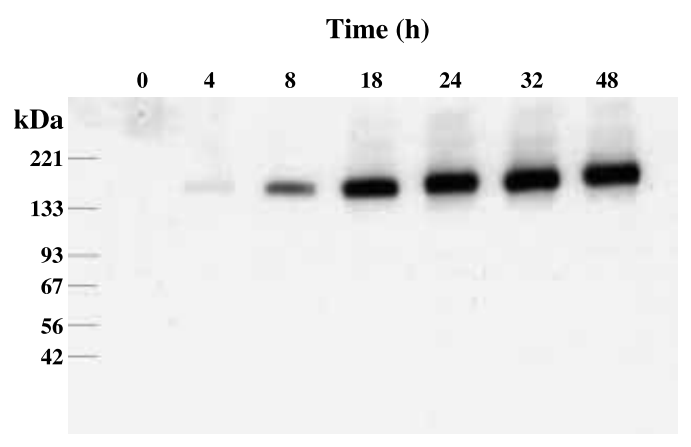

B

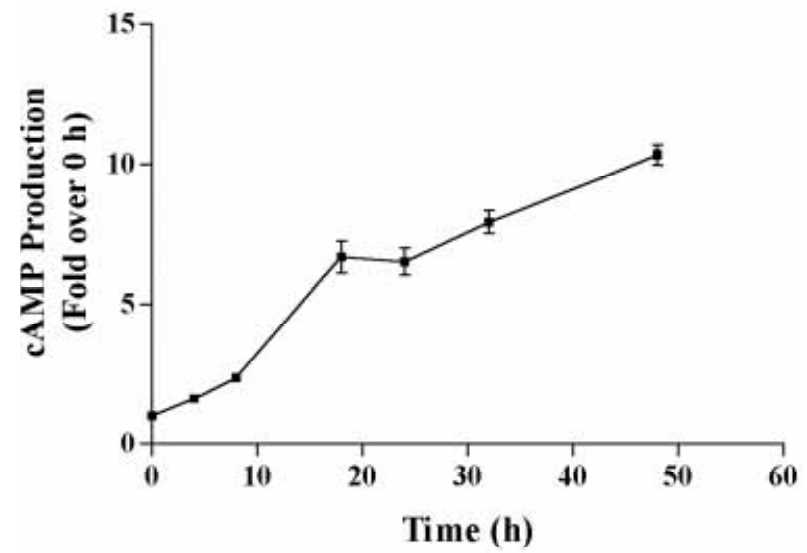

C

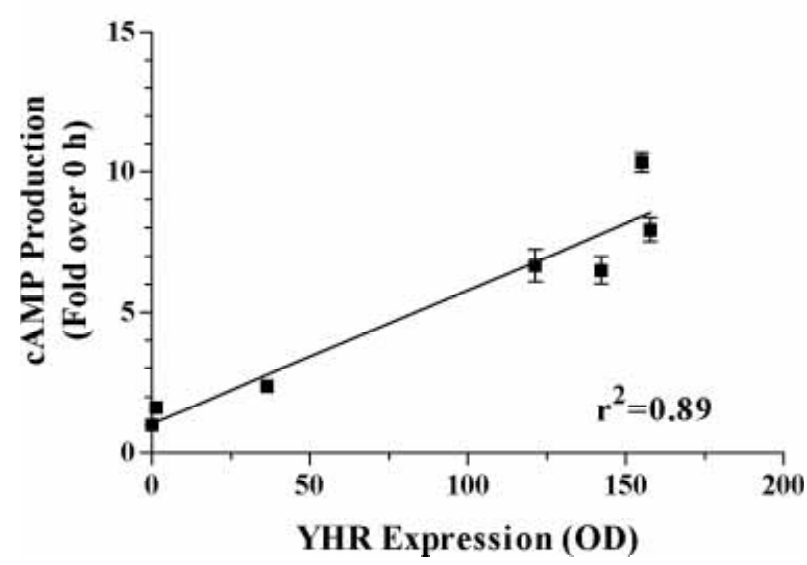

Figure 5 Time course of Dox stimulation of YHR expression. YHRtet-16 cells were incubated with $2 \mu \mathrm{g} / \mathrm{ml}$ Dox for 0 to $48 \mathrm{~h}$. Western blot (A) and cAMP production (B) assays were performed to assess the level of YHR expression. Data are means \pm ranges of two independent experiments. (C) Densitometry was performed on the X-ray film from the Western blot, and YHR expression was graphed versus cAMP production and fitted by a linear least squares analysis. synthesis (Roche, Indianapolis, IN, USA). Following washing (30 min at room temperature in $2 \times \mathrm{SSC}, 0.5 \% \mathrm{SDS}$ and $30 \mathrm{~min}$ at $50{ }^{\circ} \mathrm{C}$ in $0 \cdot 1 \times \mathrm{SSC}, \quad 0 \cdot 1 \% \quad \mathrm{SDS})$, the membrane was exposed to film for autoradiography.

\section{Densitometry to determine relative expression levels}

In order to determine the relative protein or mRNA expression levels, densitometry was performed on the X-ray film from Western blots and Northern blots utilizing a Fluor-S MultiImager (BioRad). Scans of X-ray film were analyzed with Quantity One software (BioRad), and the intensity of individual bands was determined and expressed as total optical density (OD).

\section{Curve fitting}

Graphs were produced by Prism 3.0 (GraphPad Software, Inc., San Diego, CA, USA). Linear regressions were performed utilizing the least squares fit, and curve fitting for decay experiments was determined using the equation for exponential decay.

\section{Results}

\section{Loss of YHR in stable lines}

Determination of relative expression levels in YHR-expressing cells during transient transfection is difficult since YHR does not bind exogenously added hormone (Wu et al. 1996). In order to normalize the expression levels so that the signaling properties could be better studied, stable lines expressing YHR under the control of the GMV promoter were established in HEK 293 cells. During the time course of experiments measuring the signaling of YHR, it was determined by Western blot analysis that YHR expression in the stable lines decreased, starting in early passages and undetectable by passage 11 (Fig. 2A). The two protein bands of approximately 155 and $125 \mathrm{kDa}$ that were detected with the CTP antibody most likely represent the mature and immature forms respectively of the YHR complex, the latter with incomplete carbohydrate processing. The basal levels of cAMP production over mock-transfected (MT) levels also decreased with passage number 
(Fig. 2B). Even though the receptor is not detected by Western blot at passage 13, the small increase in cAMP over MT levels suggests that a small amount of YHR is still present.

\section{Generation of tetracycline-responsive clonal lines}

In order to establish a cell line with a more constant level of YHR expression, tet-responsive cell lines were generated. After initial attempts to

$\mathbf{A}$

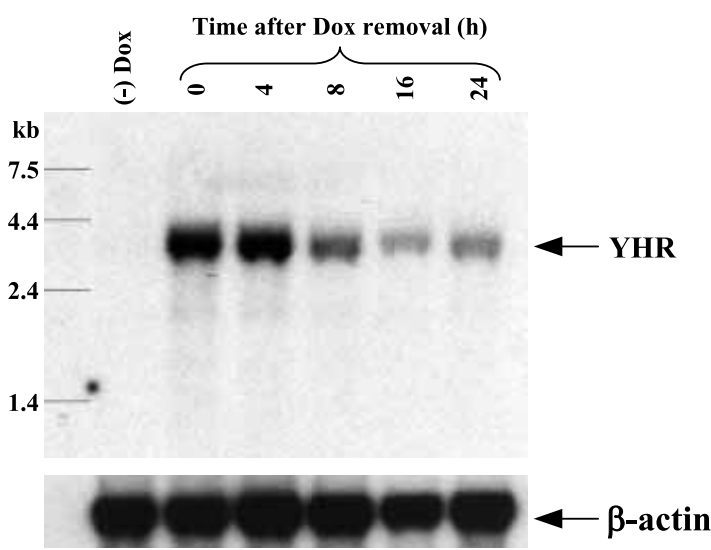

B

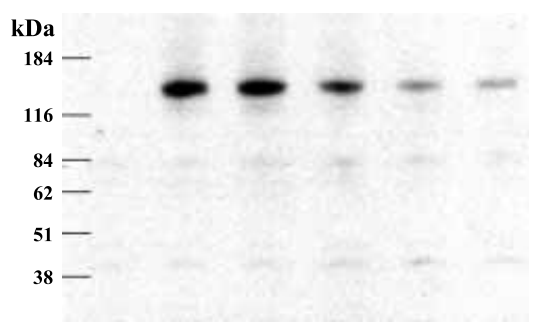

C

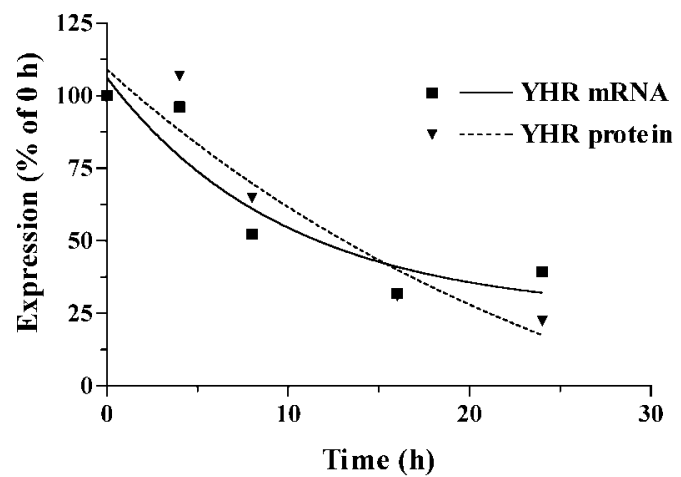

www.endocrinology.org generate stably transfected lines failed due to the necessity of co-transfection of the $\mathrm{Hyg}$ resistant plasmid and the TRE containing plasmid into HEK 293 Tet-on cells, the pTRE and pTK-Hyg plasmids were combined (Fig. 1), and YHR was cloned into the multiple cloning site. Upon transfection with the pTK-Hyg/pTRE-YHR plasmid, several clonal lines were established. Screening of these lines by Western blots in the presence and absence of Dox demonstrated three different types of clones (Fig. 3A). YHRtet-14 showed no expression of YHR; YHRtet-11 and -20 had high basal levels of expression in the absence of Dox; and YHRtet-3, -10, and -16 exhibited no basal expression of YHR but high levels could be induced in the presence of Dox. Except for clone 20, only a single protein band corresponding to the mature form of YHR with a molecular mass of approximately $155 \mathrm{kDa}$ was detected, suggesting that the YHR protein is more efficiently processed to the mature form in the tetracycline-regulated cell lines. cAMP production by the clones (Fig. 3B) correlated with the expression levels of YHR on the Western blots. Due to its better viability over other lines, YHRtet-16 was chosen for further characterization.

\section{YHR expression responds to both the dose and time of Dox stimulation}

In order to characterize the responsiveness of YHR expression to Dox, YHRtet-16 from passage 9 was incubated with varying concentrations of Dox from 0 to $4 \mu \mathrm{g} / \mathrm{ml}$ for $48 \mathrm{~h}$. Western blot analysis of total

Figure 6 Decrease in YHR expression following removal of Dox. YHRtet-16 cells were incubated with $2 \mu \mathrm{g} / \mathrm{ml}$ Dox for $24 \mathrm{~h}$. Following removal of Dox and washing, cells were incubated for 0 to $24 \mathrm{~h}$ in the absence of Dox. Northern blot (A) and Western blot (B) analyses were performed to assess YHR expression. A $\beta$-actin probe was utilized as a control for mRNA levels on the Northern blot. RNA size and molecular mass standards are shown on Northern and Western blots respectively. (C) Degradation of YHR mRNA and protein. The percentage of YHR mRNA and protein compared with $\mathrm{O} \mathrm{h}$ was calculated from the densitometric quantification of the Northern and Western blots, with the signal from actin being used to normalize the values for the Northern blot. Curves fitted to the exponential decay equations gave the following results: $r^{2}=0.87$, RNA; $r^{2}=0.91$, protein. 
membrane preparations revealed that the expression of YHR is detectable with $0 \cdot 1 \mu \mathrm{g} / \mathrm{ml}$ and was maximal with $2 \mu \mathrm{g} / \mathrm{ml}$ Dox (Fig. 4A). The production of basal cAMP shows a similar pattern of increase (Fig. 4B). The intensity of the YHR bands on the Western blot was quantified by densitometry, and when graphed against cAMP production, a good correlation $\left(r^{2}=0 \cdot 89\right)$ between YHR expression and cAMP levels was obtained (Fig. 4G).

A time course of Dox stimulation was performed in order to determine the time necessary for maximum YHR expression. YHRtet-16 cells from passage 10 were incubated with $2 \mu \mathrm{g} / \mathrm{ml}$ Dox for 0 to $48 \mathrm{~h}$. Expression was measured as early as $4 \mathrm{~h}$ after Dox addition and was maximal by $24 \mathrm{~h}$ (Fig. 5A). cAMP production showed a slight increase for the 4 and $8 \mathrm{~h}$ time points and was much higher and nearly constant from 18-24 h (Fig. 5B). The levels of YHR expression estimated from Western blot analysis and cAMP production show a good correlation $\left(r^{2}=0 \cdot 89\right.$, Fig. $\left.5 \mathrm{C}\right)$. Changing the media after $18 \mathrm{~h}$ to replenish the Dox did not have an effect on YHR expression compared with cells where the media was not changed (data not shown), demonstrating that the plateau in YHR expression does not result from a decrease in the concentration of Dox.

\section{Decrease in YHR expression following Dox removal}

In order to follow the deinduction of YHR expression, YHRtet-16 cells were incubated for $24 \mathrm{~h}$ with $2 \mu \mathrm{g} / \mathrm{ml}$ Dox, then washed to remove any excess Dox, and incubated for various times followed by mRNA isolation. Northern blot analysis was performed to determine YHR mRNA levels (Fig. 6A). YHR mRNA levels, normalized to the level of the control $\beta$-actin signal, decreased slowly during the first $4 \mathrm{~h}$ without Dox, then declined to $40 \%$ at $24 \mathrm{~h}$. Similarly, Western blot analysis (Fig. 6B) of similarly treated cells showed that YHR protein expression remained constant for the first $4 \mathrm{~h}$, then decreased to $22 \%$ at $24 \mathrm{~h}$. These results demonstrate that YHR expression levels in HEK 293 cells are highly dependent on the presence of mRNA (Fig. 6G), indicating the rapid degradation of the constitutively active receptor. These results, however, do not allow for an accurate determination of the turnover rate of
YHR because of the possibility of de novo protein production from the mRNA still present after $24 \mathrm{~h}$.

\section{Discussion}

The unexplained loss of YHR in stably transfected HEK 293 cells prompted us to establish the regulated expression of YHR under the control of a tetracyline-responsive promoter. Characterization of one of the YHR-tet clonal lines revealed the rapid, controlled, and sustained induction of YHR expression by the Tet-on system following the addition of Dox. The decrease in YHR expression following Dox removal was slow with $40 \%$ of the mRNA still remaining after $24 \mathrm{~h}$.

The dose-response and time-course experiments established not only the controlled expression of YHR, but also demonstrated that cAMP production by YHR is directly proportional to the level of receptor expression. Previously, this correlation could not be determined (Wu et al. 1996) because of the variability of expression levels in transient transfections. Additionally, these experiments utilized YHRtet-16 cells from later passages, indicating that expression of YHR is consistent over time unlike the HEK 293 stable line for YHR which lost receptor expression when continually passaged.

The protein levels as determined by Western blot analysis closely mimic the levels of mRNA. These results suggest that the turnover rate of the constitutively active YHR is high, which is consistent with previous studies of mutationinduced constitutively active LHR (Min et al. 1998, Bradbury \& Menon 1999, Min \& Ascoli 2000). In the studies with constitutively active LHR, the rates of LHR internalization and down regulation were determined by following the fate of ${ }^{125} \mathrm{I}-\mathrm{hCG}$ bound to the receptor on the surface of the cell. Again, this type of study is not possible in the case of YHR since it does not bind exogenous hCG $(\mathrm{Wu}$ et al. 1996).

An accurate assessment of the degradation of YHR, however, could not be determined utilizing the Tet-on system because of the slow decline in the mRNA levels following removal of Dox. These results are consistent with a study on the effectiveness of different tetracycline analogs which showed that Dox had the longest delay of all of the analogs tested in returning the system to 
pre-stimulation levels (A-Mohammadi et al. 1997). However, since the Tet-on system only responds to Dox (Gossen et al. 1995), no other analogs could be utilized to control YHR expression. Nonetheless, this system is good for turning on and controlling expression but is not necessarily the best for following protein decay.

In summary, tetracycline-regulated expression of YHR has been established in HEK 293 cells, and we showed that the levels of expression are tightly controlled by the dose and time of Dox exposure. These results establish the ability to express YHR in a regulated manner which can be further utilized to study the signaling pathways activated by varying levels of constitutive receptor activation in cell culture. The system will also be useful in transgenic mice to determine the reproductive effects of YHR activation at various times in development.

\section{Acknowledgements}

This research was supported by the University of Georgia Research Foundation, Inc. and by NIH Research Grant DK33973.

\section{References}

A-Mohammadi S, Alvarez-Vallina L, Ashworth LJ \& Hawkins RE 1997 Delay in resumption of the activity of tetracyclineregulatable promoter following removal of tetracycline analogues. Gene Therapy 4 993-997.
Ascoli M, Fanelli F \& Segaloff DL 2002 The lutropin/ choriogonadotropin receptor, a 2002 perspective. Endocrine Reviewes 23 141-174.

Bradbury F \& Menon KMJ 1999 Evidence that constitutively active luteinizing hormone/human chorionic gonadotropin receptors are rapidly internalized. Biochemistry 38 8703-8712.

Gossen M \& Bujard H 1992 Tight control of gene expression in mammalian cells by tetracycline-responsive promoters. PNAS $\mathbf{8 9}$ $5547-5551$.

Gossen M, Freundlieb S, Bender G, Muller G, Hillen W \& Bujard H 1995 Transcriptional activation by tetracyclines in mammalian cells. Science $\mathbf{2 6 8} 1766-1769$.

Meehan TP, Harmon BG, Camper S, Puett D \& Narayan P 2002 Phenotypic effects of a constitutively active lutropin receptor in transgenic male mice. Biology of Reproduction 66 (Suppl 1) 22 (Abstract 56).

Min L \& Ascoli M 2000 Effect of activating and inactivating mutations on the phosphorylation and trafficking of the human lutropin/choriogonadotropin receptor. Molecular Endocrinology 14 1797-1810.

Min K-S, Liu X, Fabritz J, Jaquette J, Abell AN \& Ascoli M 1998 Mutations that induce constitutive activation and mutations that impair signal transduction modulate the basal and/or agoniststimulated internalization of the lutropin/choriogonadotropin receptor. Fournal of Biological Chemistry 273 34911-34919.

Narayan P, Gray J \& Puett D 2002 Yoked complexes of human choriogonadotropin and the lutropin receptor: evidence that monomeric individual subunits are inactive. Molecular Endocrinology $162733-2745$.

Shenker A 2002 Activating mutations of the lutropin/ choriogonadotropin receptor in precocious puberty. Receptors and Channels 8 3-18.

Themmen APN \& Huhtaniemi IT 2000 Mutations of gonadotropins and gonadotropin receptors: elucidating the physiology and pathophysiology of pituitary-gonadal function. Endocrine Reviews $\mathbf{2 1}$ 551-583.

Wu C, Narayan P \& Puett D 1996 Protein engineering of a novel constitutively active hormone-receptor complex. Foumal of Biological Chemistry 271 31638-31642.

Received in final form 8 August 2003 Accepted 5 September 2003 